\title{
A Facile Route to the Preparation of Highly Uniform ZnO@TiO 2 Core-Shell Nanorod Arrays with Enhanced Photocatalytic Properties
}

\author{
Yuanyuan Zhao, Peifei Tong, Dong Ma, Bing Li, Qinzhuang Liu, \\ San Chen, and Yongxing Zhang \\ Collaborative Innovation Center of Advanced Functional Composites, Huaibei Normal University, Huaibei 235000, China \\ Correspondence should be addressed to Yongxing Zhang; zyx07157@mail.ustc.edu.cn
}

Received 14 January 2017; Revised 14 March 2017; Accepted 20 March 2017; Published 11 April 2017

Academic Editor: Roberto Comparelli

Copyright (c) 2017 Yuanyuan Zhao et al. This is an open access article distributed under the Creative Commons Attribution License, which permits unrestricted use, distribution, and reproduction in any medium, provided the original work is properly cited.

Design and synthesis of $\mathrm{ZnO} @ \mathrm{TiO}_{2}$ core-shell nanorod arrays as promising photocatalysts have been widely reported. However, it

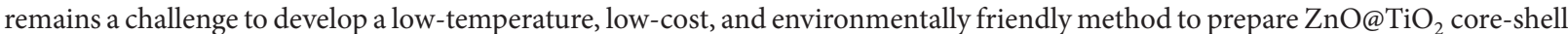
nanorod arrays over a large area for future device applications. Here, a facile, green, and efficient route is designed to prepare the $\mathrm{ZnO@TiO} 2$ nanorod arrays with a highly uniform core-shell structure over a large area on $\mathrm{Zn}$ wafer via a vapor-thermal method at relatively low temperature. The growth mechanism is proposed as a layer-by-layer assembly. The photocatalytic decomposition

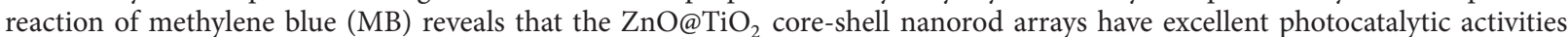
when compared with the performance of the $\mathrm{ZnO}$ nanorod arrays. The improved photocatalytic activity could be attributed to the core-shell structure, which can effectively reduce the recombination rate of electron-hole pairs, significantly increase the optical absorption range, and offer a high density of surface active catalytic sites for the decomposition of organic pollutants. In addition, it

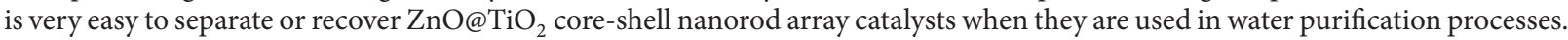

\section{Introduction}

In recent years, there has been increasing interest in the design and synthesis of $\mathrm{ZnO} @ \mathrm{TiO}_{2}$ core-shell nanorod arrays to improve the quantum efficiency of Dye-Sensitized Solar Cells (DSSC), highly transparent self-cleaning coating for LEDs, and photocatalysts for the decomposition of organic pollutants in waste water [1-10]. This is mainly attributed that the large binding energy of $\mathrm{ZnO}$ and the high reactivity of $\mathrm{TiO}_{2}$ can significantly increase the process of electron and hole transfer between the corresponding conduction and valence bands. Thus, compared with photoanode materials or single metal oxide catalysts [11-18], a better separation of photogenerated carriers can be obtained in $\mathrm{ZnO} @ \mathrm{TiO}_{2}$ core-shell structures.

Until now, several types of $\mathrm{ZnO} @ \mathrm{TiO}_{2}$ core-shell nanorod arrays are fabricated by different methods. Typically, Wang et al. have prepared $\mathrm{ZnO} / \mathrm{TiO}_{2}$ core-shell nanorod arrays by a plasma sputtering decoration route [19]. Heterostructure $\mathrm{ZnO} / \mathrm{TiO}_{2}$ core-brush nanostructures are synthesized on glass substrates by a combination of aqueous solution growth and magnetron sputtering method $[6,20]$. Greene et al. have reported that the $\mathrm{TiO}_{2}$ shells are grown on the $\mathrm{ZnO}$ nanorod arrays in a traveling-wave atomic layer deposition (ALD) system using $\mathrm{TiCl}_{4}$ and water at $300^{\circ} \mathrm{C}$ with

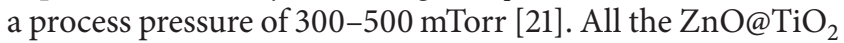
core-shell nanorod arrays in the above-mentioned reports are obtained under severe conditions (including low pressure, relatively high temperature, and anaerobic conditions); and special equipment is required. Thus, it remains a challenge to develop a low-temperature, low-cost, and environmentally friendly method to prepare $\mathrm{ZnO} @ \mathrm{TiO}_{2}$ core-shell nanorod arrays over a large area for future device applications.

Herein, a facile, green, and efficient route is proposed to achieve a decoration of $\mathrm{ZnO}$ nanorod arrays with $\mathrm{TiO}_{2}$ nanoparticle via a vapor-thermal method at relatively low 


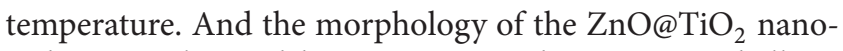
rod arrays obtained heterostructure shows a core-shell arrangement with a highly uniform over a large area on $\mathrm{Zn}$ wafer. A $60 \mathrm{~mL}$ stainless steel autoclave with a Teflon liner is used to achieve the preparation process, which is simpler equipment than magnetron sputtering system and ALD system that had been widely used previously. The growth mechanism of the $\mathrm{ZnO} @ \mathrm{TiO}_{2}$ nanorod arrays is discussed. The high UV light photocatalytic efficiency of the product is achieved

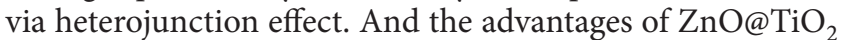
heterostructures have the following features: (a) the $\mathrm{ZnO} @ \mathrm{TiO}_{2}$ core-shell structure heterojunction can improve electron-charge separation efficiency. So, the proposed route to prepare the $\mathrm{ZnO} @ \mathrm{TiO}_{2}$ core-shell nanorod arrays represents a significant advance for the degradation of organic pollutants in water; (b) compared with some nanoscale catalyst particles, the $\mathrm{ZnO} @ \mathrm{TiO}_{2}$ film with a core-shell structure has unique advantages for practical applications from the aspect of long life, low-cost, and high degradation efficiency. Particularly, when $\mathrm{TiO}_{2}$ nanoparticles are coated on the surface of $\mathrm{ZnO}$ nanorod arrays, it is very convenient to separate or recover them in water purification processes; (c) $\mathrm{ZnO}$ is sensitive to both acidic and basic solutions (chemical corrosion). However, when the outer $\mathrm{TiO}_{2}$ layers are formed on the surface of $\mathrm{ZnO}$ nanorod arrays, they can serve as protective layers in solutions.

\section{Experimental}

2.1. Preparation of Highly Uniform $\mathrm{ZnO@TiO} 2$ Core-Shell $\mathrm{Na}$ norod Arrays. All reagents were purchased from Sinopharm Chemical Reagent Co., Ltd. (China). The reagents were of analytical grade and used without further purification. The $\mathrm{ZnO} @ \mathrm{TiO}_{2}$ nanorod arrays on $\mathrm{Zn}$ wafer were prepared by following two steps: firstly, a piece of zinc wafer $(1 \mathrm{~cm} \times 1 \mathrm{~cm}$, 99.99\%) pretreated by sonication in ethanol and deionized water and dried in air was placed in a sealed bottle containing of zinc nitrate hydrate $(0.1 \mathrm{M})$ and hexamethylenetetramine $(0.1 \mathrm{M})$ for three hours at $75^{\circ} \mathrm{C}$. The $\mathrm{ZnO}$ nanorod arrays were obtained. The samples were rinsed with deionized water for several times and dried at $60^{\circ} \mathrm{C}$ for several hours before

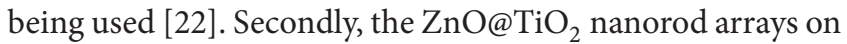
$\mathrm{Zn}$ wafer were prepared by the vapor-thermal method using tetrabutyl titanate (TBOT) as the titanium source. In a typical procedure, the piece of zinc wafer with $\mathrm{ZnO}$ nanorod arrays $(1 \mathrm{~cm} \times 1 \mathrm{~cm})$ was placed $10 \mathrm{~mL}$ beaker with the mixture of ethanol and TBOT. Then, the beaker was placed into a $60 \mathrm{~mL}$ stainless steel autoclave with a Teflon liner. The free space between the Teflon liner and the beaker was filled with distilled water. After sealing, the autoclave was heated to $150^{\circ} \mathrm{C}$ for $6 \mathrm{~h}$. At the end of the reaction, the autoclave was cooled naturally to room temperature, and the products were collected and washed for three cycles using deionized water and ethanol, respectively. And then, they were dried at $50^{\circ} \mathrm{C}$ in a vacuum oven for $3 \mathrm{~h}$.

2.2. Characterization. The surface morphologies of the products were examined by Field emission scanning electron microscope (FESEM, Quanta 200 FEG). Transmission electron microscopy (TEM), high resolution transmission electron microscope (HRTEM) images, and selected area energy dispersive X-ray spectrum (EDS) were obtained on a JEOL2012 TEM coupled with an EDS detector, operated at an acceleration voltage of $200 \mathrm{kV}$. The UV-Vis spectra were measured by a UV/Vis/NIR spectrophotometer (Hitachi U-4100).

2.3. Photocatalytic Properties. In our experiments, photocatalytic decomposition of MB under UV light illumination has been conducted at room temperature. Both the $\mathrm{ZnO}$ nanorod arrays and $\mathrm{ZnO} @ \mathrm{TiO}_{2}$ nanorod arrays grown on $\mathrm{Zn}$ wafer with size $1 \mathrm{~cm} \times 1 \mathrm{~cm}$ were soaked into two identical bottles containing methylene blue $\left(\mathrm{MB}, 10 \mathrm{~mL}, 1 \times 10^{-5} \mathrm{M}\right)$. Before UV light illumination $(\lambda: 254 \mathrm{~nm}$, output power: $8 \mathrm{~W}$, the irradiance of the UV light source is $20 \mu \mathrm{W} / \mathrm{cm}^{2}$ ), they were stored in the dark for $30 \mathrm{~min}$ to ensure the establishment of an adsorption equilibrium for $\mathrm{MB}$ at ambient temperature. In addition, in order to ensure that both the samples could receive the same amount of UV illumination, they were placed $5 \mathrm{~cm}$ away from the UV light sources in our experiments. As a comparison, one bottle containing blank $\mathrm{MB}$ solution was also carried out under the same condition. The concentrations of $\mathrm{MB}$ in the above three bottles at given time intervals were determined using a UV/Vis/NIR spectrophotometer (Hitachi U-4100).

\section{Results and Discussion}

Figures 1(a) and 1(b) show scanning electron microscope (SEM) images of the $\mathrm{ZnO}$ nanorod arrays grown on $\mathrm{Zn}$ wafer. The low-magnification SEM image (Figure 1(a)) shows a large area uniform film-like structure deposited on the wafer. From the high-magnification SEM image (Figure 1(b)), it is clear that high density $\mathrm{ZnO}$ nanorod arrays are grown vertically on the $\mathrm{ZnO}$ wafer. These nanorods have a nearly uniform diameter of 180-200 nm. The inset in Figure 1(b) is the TEM image of a single $\mathrm{ZnO}$ nanorod with length about $1.4 \mu \mathrm{m}$. From the image, it is confirmed that the diameter of $\mathrm{ZnO}$ nanorod is about $190 \mathrm{~nm}$. Figures 1(c) and 1(d) show SEM images of

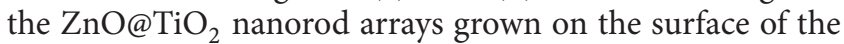
$\mathrm{Zn}$ wafer. The low-magnification image (Figure 1(c)) also displays a large scale uniform film-like structure grown on the $\mathrm{ZnO}$ wafer. Figure 1(d) shows the high-magnification SEM

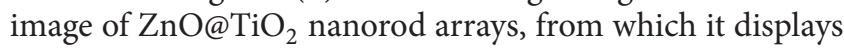
that high density $\mathrm{ZnO} @ \mathrm{TiO}_{2}$ nanorod arrays with the diameter of about 230-260 $\mathrm{nm}$ are grown vertically on the surface of the $\mathrm{ZnO}$ wafer. From the high-magnification images (Figures

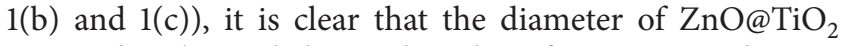
nanorod is obviously larger than that of $\mathrm{ZnO}$ nanorod.

The high-magnification SEM image shown in Figure 2(a) further observes the detailed structures of ${\mathrm{ZnO} @ \mathrm{TiO}_{2}}$

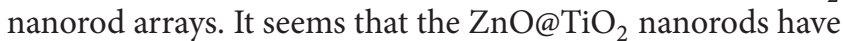
core-shell structures (the black and white arrows indicate the shell structure and the core structure, resp.). In addition, the open tip of $\mathrm{ZnO} @ \mathrm{TiO}_{2}$ nanorod shown in Figure 2(a) reveals the top of $\mathrm{ZnO}$ nanorod structure (indicated by the black dotted circle). Figure 2(b) shows that the inner edge of the 


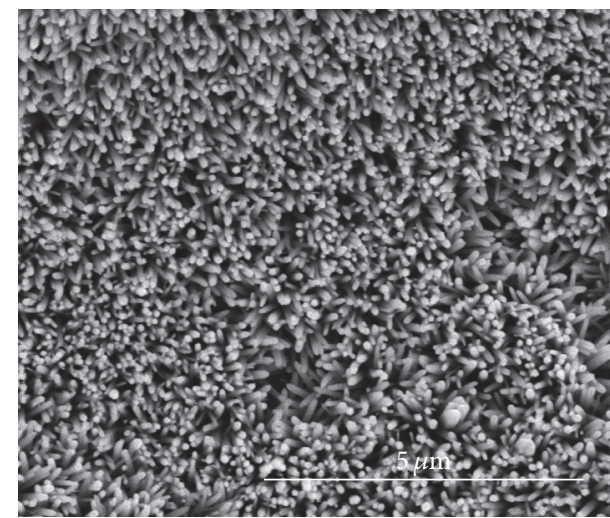

(a)

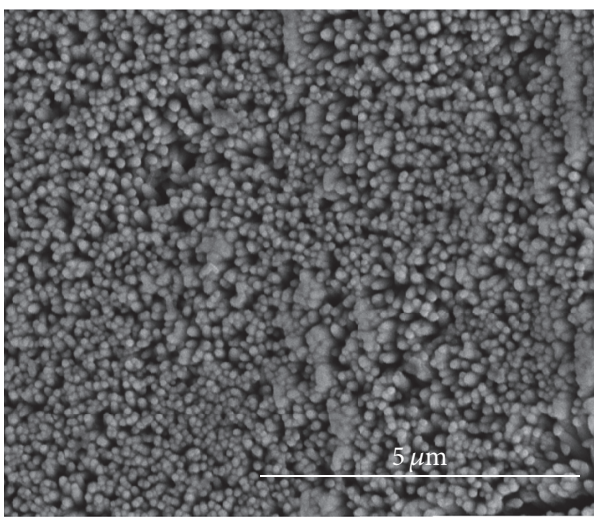

(c)

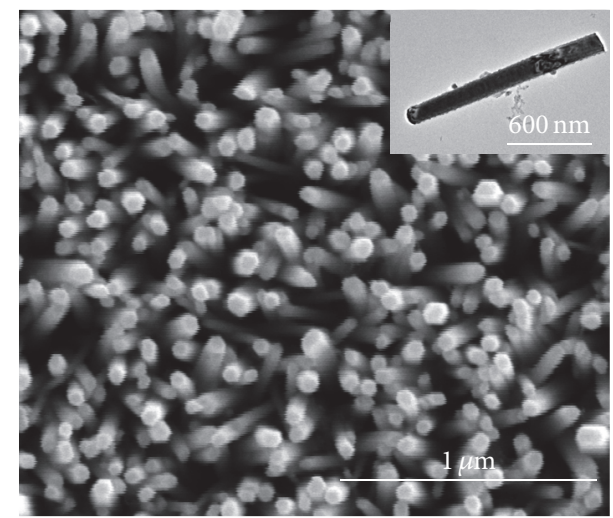

(b)

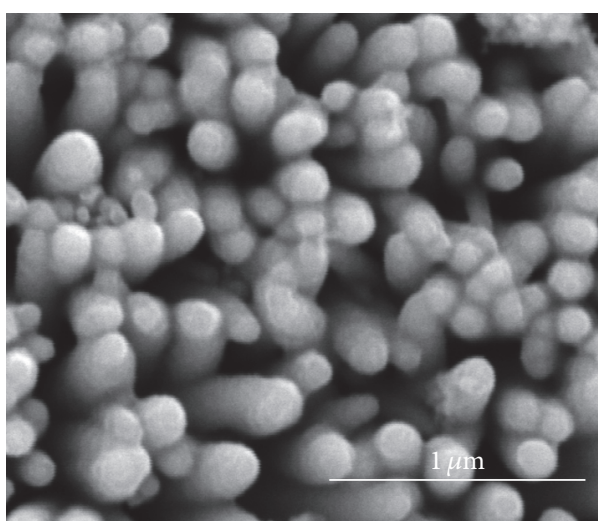

(d)

FIGURE 1: SEM (a) and high resolution SEM (b) of ZnO nanorod arrays (inset of Figure (b): TEM of ZnO nanorod); SEM (c) and high resolution SEM (d) of $\mathrm{ZnO@} \mathrm{TiO}_{2}$ nanorod arrays.

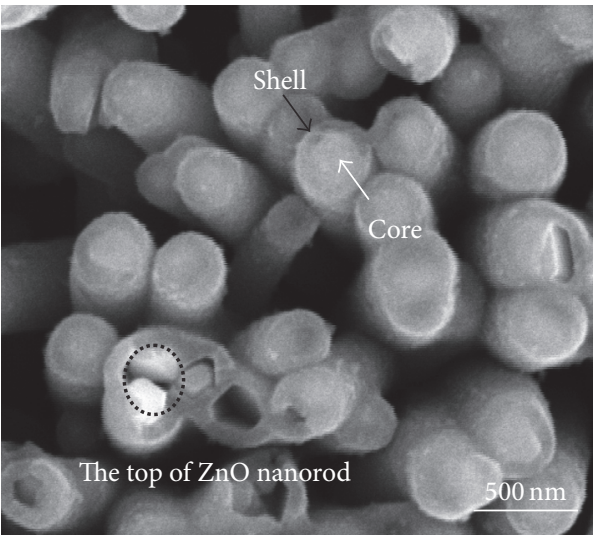

(a)

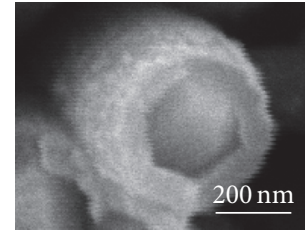

(b)

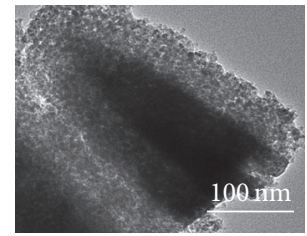

(c)

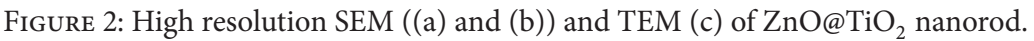

$\mathrm{TiO}_{2}$ shell and the outer edge of $\mathrm{ZnO}$ core have hexagonal structures. The thickness of the $\mathrm{TiO}_{2}$ shell is about $40-60 \mathrm{~nm}$. The TEM image shown in Figure 2(c) clearly confirms that the $\mathrm{ZnO@TiO} 2$ nanorod has core-shell structure. The $\mathrm{TiO}_{2}$ shell thickness of $50 \mathrm{~nm}$ is consistent with the result of the observation from Figure 2(b).
Figure 3 shows the TEM image and the corresponding energy dispersive spectroscopic (EDS) analysis of $\mathrm{ZnO} @ \mathrm{TiO}_{2}$ nanorod. In the top right corner of Figure 3(a), the lattice fringe spacing of $0.525 \mathrm{~nm}$ observed from the HRTEM image corresponded to the (001) plane of hexagonal $\mathrm{ZnO}$ phase (JCPDS card number 00-005-0664, space group: P63mc 


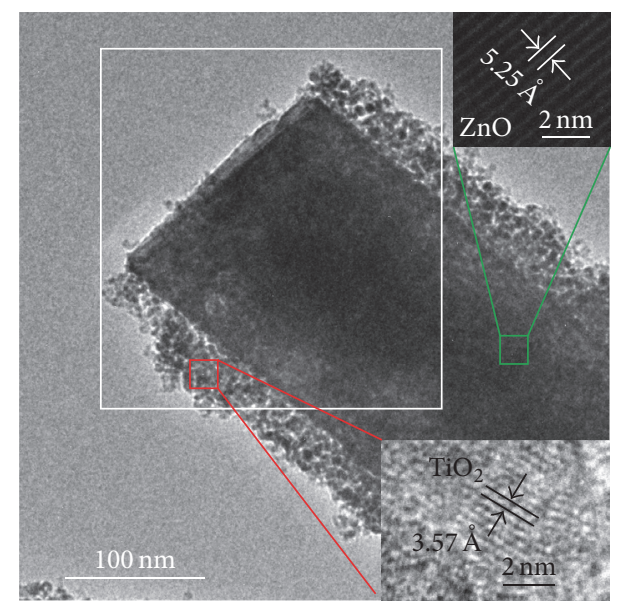

(a)

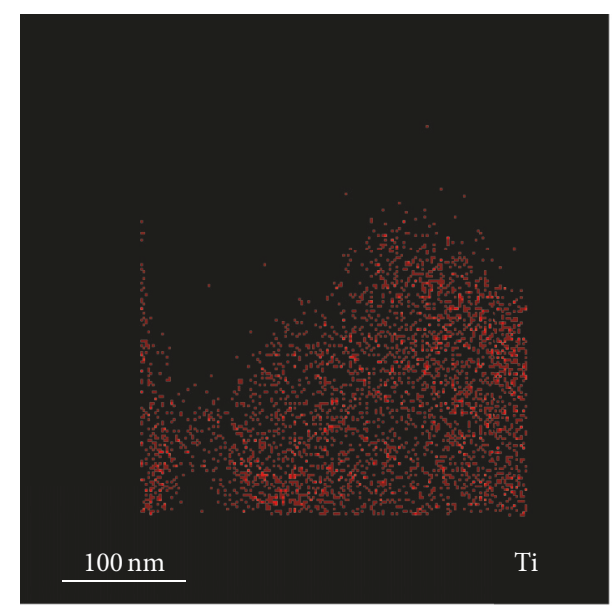

(c)

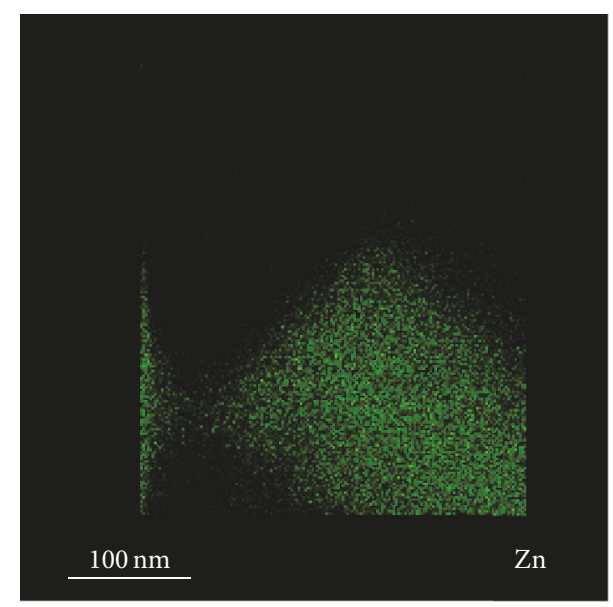

(b)

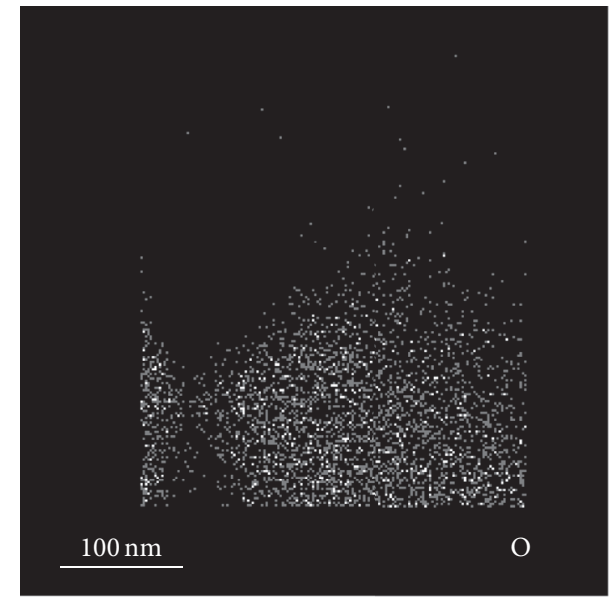

(d)

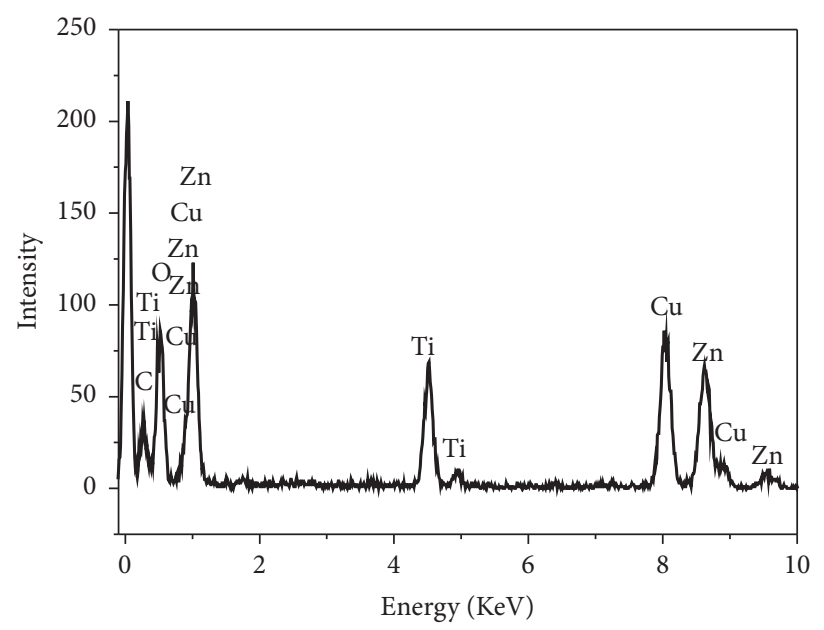

(e)

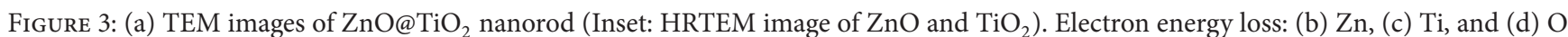

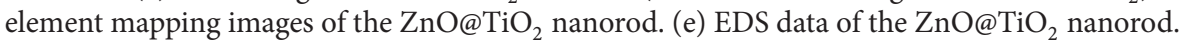




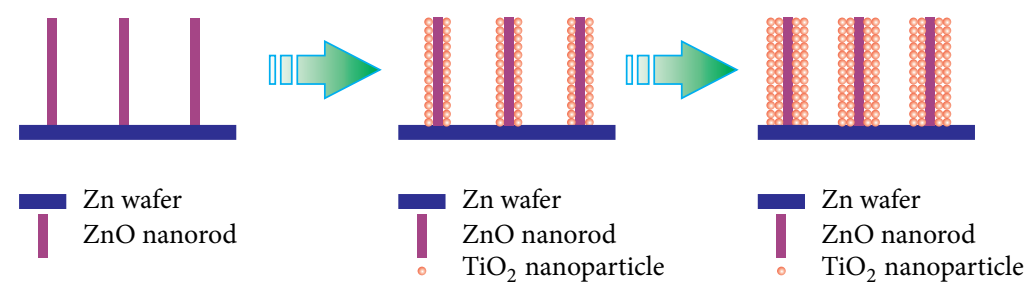

(a)

(b)

(c)

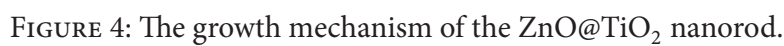

(186)) with $c$-axial growth direction. The hexagonal $\mathrm{ZnO}$ phase is identical with the reported ones [22]. The lattice fringe spacing of $0.357 \mathrm{~nm}$ observed from the HRTEM image corresponded to the (101) plane of anatase $\mathrm{TiO}_{2}$ phase in the bottom right corner of Figure 3(a) (JCPDS card number 00021-1272, space group: I41/amd (141)). This result is consistent with that reported previously [23]. In order to further confirm the presence of both $\mathrm{TiO}_{2}$ and $\mathrm{ZnO}$ components in the $\mathrm{ZnO}_{\mathrm{TiO}}$ nanorods, electron mapping image analysis is used to analyze the sample (Figures 3(a)-3(d)). The electron mapping images can be obtained via visualizing the inelastically scattered electrons in the energy loss windows for elemental $\mathrm{Zn}, \mathrm{Ti}$, and $\mathrm{O}$. The different color areas displayed in Figures 3(a)-3(d) indicate $\mathrm{Zn-}$, Ti-, and O-enriched areas of the sample, respectively, which indicate the presence of both $\mathrm{ZnO}$ and $\mathrm{TiO}_{2}$ in the $\mathrm{ZnO} @ \mathrm{TiO}_{2}$ nanorods. The images also show that the $\mathrm{ZnO} @ \mathrm{TiO}_{2}$ nanorod has very good uniform core-shell structures. The EDS analysis (Figure 3(e)) of the $\mathrm{ZnO} @ \mathrm{TiO}_{2}$ nanorods indicates the existence of $\mathrm{Zn}, \mathrm{Ti}$, and O elements (copper signals are present from the copper grid support).

The growth mechanism of the $\mathrm{ZnO} @ \mathrm{TiO}_{2}$ nanorod arrays can be described as follows. During the experiment, the ethanol evaporates firstly when the reaction system is heated. It is mainly due to the fact that the ethanol has a lower boiling point than water. And then, the water vapor promotes the hydrolysis of TBOT dissolved in ethanol. It is supposed that there are many nucleation sites on the surface of the $\mathrm{ZnO}$ nanorod. During the initial stage, $\mathrm{TiO}_{2}$ nanoparticles formed by hydrolysis of TBOT are deposited on the nucleation site of the $\mathrm{ZnO}$ surface. With the passage of reaction time (Figure 4(b)), the as-formed $\mathrm{TiO}_{2}$ nanoparticles subsequently serve as nucleation sites for further deposition of $\mathrm{TiO}_{2}$ nanoparticles (Figure 4(c)), which lead to layer-by-layer assembly.

Figure 5(a) shows the typical diffuse reflectance spectra (DRS) for $\mathrm{ZnO}$ nanorod arrays and $\mathrm{ZnO@TiO}_{2}$ nanorod arrays at room temperature. As shown in curve 1 of Figure 5(a), ZnO nanorod arrays present a continuous wide absorption band in the UV light region. When $\mathrm{TiO}_{2}$ shell is formed on the surface of $\mathrm{ZnO}$ nanorod arrays $\left(\mathrm{ZnO} @ \mathrm{TiO}_{2}\right.$ nanorod arrays), the increase in peak intensity can be observed obviously (as shown in curve 2 of Figure 5(a)). In the UV region, from 200 to $320 \mathrm{~nm}$, the peak intensity in continuous UV absorption band is stronger than that of $\mathrm{ZnO}$ nanorod arrays. The changes of UV peak intensity may be affected by scattering, particle size, aggregates, and so on [24]. In addition, as shown in Figure 5(a), a red shift of the band gap absorption edge can also be observed in the $\lambda>320 \mathrm{~nm}$ region. To determine the band gaps of the $\mathrm{ZnO} @ \mathrm{TiO}_{2}$ nanorod heterostructures, we replotted the spectra shown in Figure 5(a) in the form shown in the inset image of Figure 5(a) obtained by the application of the Kubelka-Munch algorithm [14]. From the inset image of Figure 5(a), the estimated band gap of the $\mathrm{ZnO} @ \mathrm{TiO}_{2}$ is $2.95 \mathrm{eV}$, which is smaller than that of $\mathrm{ZnO} 3.01 \mathrm{eV}$. This may be due to the formation of a $\mathrm{ZnO} @ \mathrm{TiO}_{2}$ heterojunction slowing the electron-hole recombination and hence reducing the level of emission. Thus, the photocatalytic ability of the $\mathrm{ZnO} @ \mathrm{TiO}_{2}$ heterostructures is improved, which is demonstrated by the following photocatalytic experiments.

As shown in Figure 5(b), the MB decomposition rates of the samples are compared over a period of time. The MB decomposition rate in the bottle containing blank MB solution with catalysts is only about $12 \%$ after $200 \mathrm{~min}$ of photocatalytic reaction. However, $60 \%$ and $86 \%$ of $\mathrm{MB}$ concentration are decomposed by the $\mathrm{ZnO}$ nanorod arrays and $\mathrm{ZnO} @ \mathrm{TiO}_{2}$ nanorod arrays grown on $\mathrm{Zn}$ wafer, respectively.

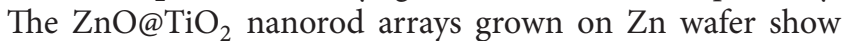
superior photocatalytic activity to the $\mathrm{ZnO}$ nanorod arrays grown on $\mathrm{Zn}$ wafer. This can be attributed to the formation of the P-N core-shell heterojunction between $\mathrm{ZnO}$ and $\mathrm{TiO}_{2}$. The P-N core-shell heterojunction can enhance the charge separation effect under UV illumination. Thus, the composite nanostructures can further promote the photocatalytic activity $[6,11,25,26]$. In addition, the comparison with the photocatalytic activity of the conventional benchmark $\left(\mathrm{TiO}_{2} \mathrm{P} 25\right.$ Evonik) has also been investigated. From Figure 5(b), it is clear that the photocatalytic degradation capacity of $\mathrm{TiO}_{2}$ (P25 Evonik) particles is higher than that of the ${\mathrm{ZnO} @ \mathrm{TiO}_{2}}$ films with a core-shell structure. However, compared with $\mathrm{TiO}_{2}$ (P25 Evonik) particles, the $\mathrm{ZnO} @ \mathrm{TiO}_{2}$ films with a core-shell structure have unique advantages for practical applications. It is very convenient to separate or recover them in water purification processes when $\mathrm{TiO}_{2}$ nanoparticles are coated on the surface of $\mathrm{ZnO}$ nanorod arrays.

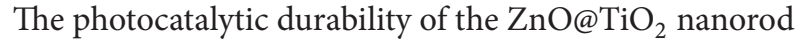
arrays is also tested. Figure 5(c) displays the cyclic photodegradation of $\mathrm{MB}$ using $\mathrm{ZnO} @ \mathrm{TiO}_{2}$ nanorod arrays. After

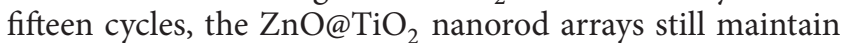
high photocatalytic ability. The core-shell structures of the 


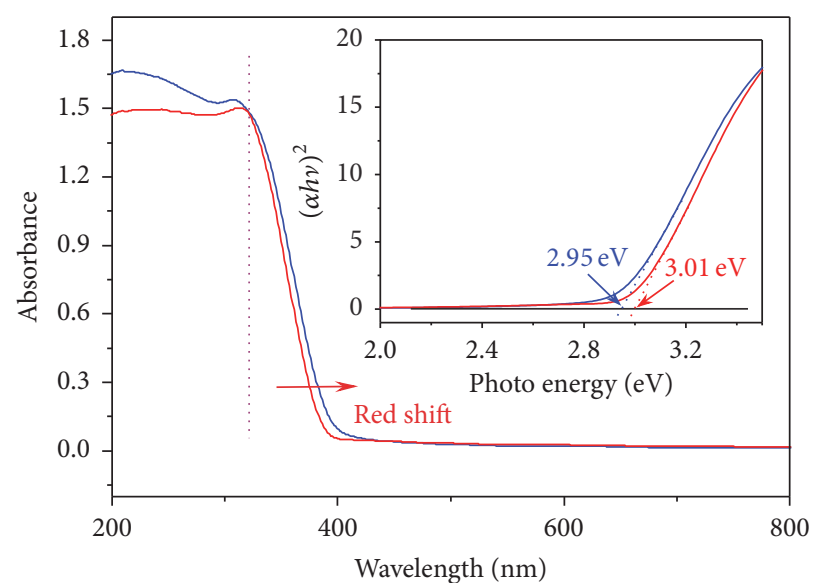

(1) $\mathrm{ZnO}$ nanorod arrays

(2) $\mathrm{ZnO@TiO}_{2}$ nanorod arrays

(a)

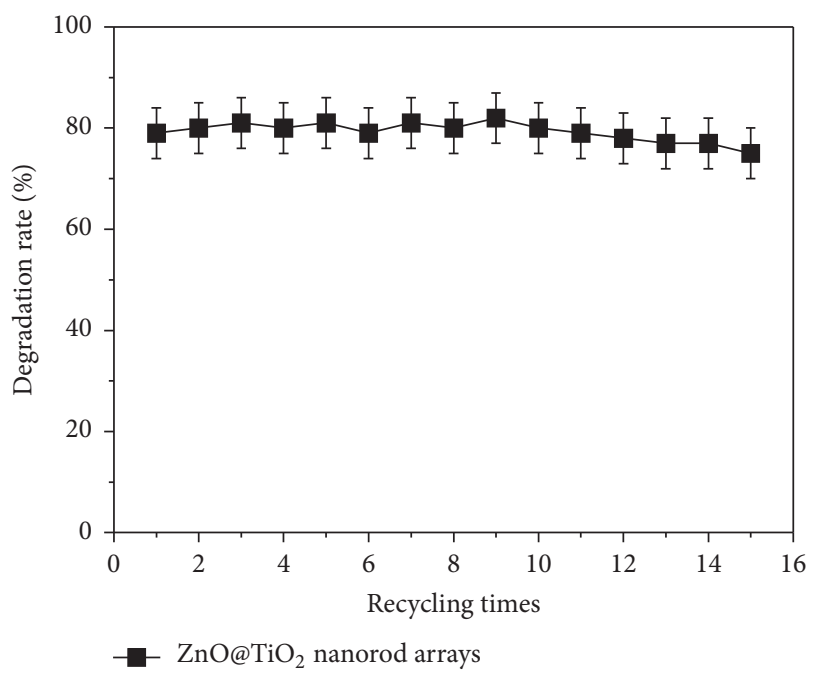

(c)

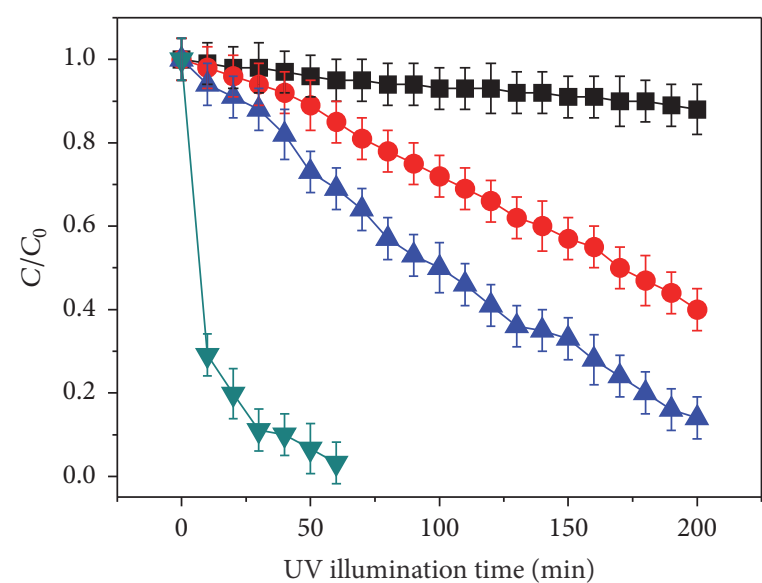

(1) No catalyst

(2) $\mathrm{ZnO}$ nanorod arrays

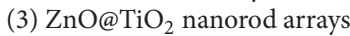

(4) $\mathrm{TiO}_{2} \mathrm{P} 25$ Evonik

(b)

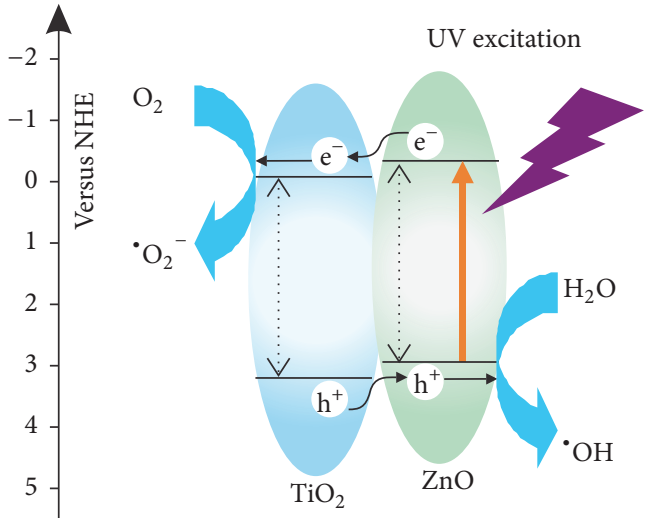

(d)

Figure 5: (a) Diffuse reflectance spectra (DRS) and (inset) plot of transferred Kubelka-Munch versus energy of the light absorbed for the

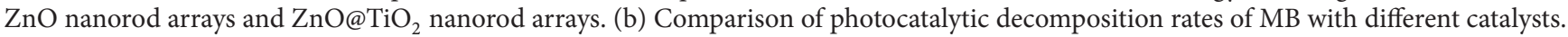
(c) Cyclic photodegradation of $\mathrm{MB}$ using $\mathrm{ZnO} @ \mathrm{TiO}_{2}$ nanorod arrays. The same $\mathrm{ZnO} @ \mathrm{TiO}_{2}$ nanorod arrays for degradation of $\mathrm{MB}$ are tested up to 15 cycles. The photocatalytic time is $180 \mathrm{~min}$ for each cycle. (d) Photogenerated electron transfer process in the $\mathrm{ZnO}_{\mathrm{O}} \mathrm{TiO}{ }_{2}$ nanorod under UV illumination. The scale bars represent the standard deviations of three replicated samples.

$\mathrm{ZnO@} \mathrm{TiO}_{2}$ nanorod arrays are expected to have a long service life. Actually, in our sample, $\mathrm{ZnO}$ is sensitive to both acidic and basic solutions (chemical corrosion). However, when the outer $\mathrm{TiO}_{2}$ layers are formed on the surface of $\mathrm{ZnO}$ nanorod arrays, they can serve as protective layers in solutions. Furthermore, the photocorrosion of $\mathrm{ZnO}$ under UV illumination can also be prevented by $\mathrm{TiO}_{2}$ layers. Photocorrosion is a very important shortcoming for photocatalysts such as CdS and $\mathrm{ZnO}$ but not for $\mathrm{TiO}_{2}[27,28]$. Thus, these

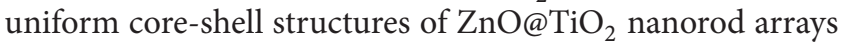
can obviously improve the efficiency and stability of the photocatalyst.

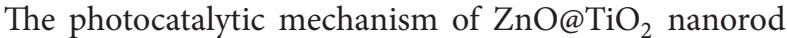
arrays for $\mathrm{MB}$ is displayed in Figure 5(d). Under UV illumination, both $\mathrm{ZnO}$ and $\mathrm{TiO}_{2}$ can absorb the photons. Thus, the electron $\left(\mathrm{e}^{-}\right)$and hole $\left(\mathrm{h}^{+}\right)$are obtained. The produced $\mathrm{e}^{-}$ transfers from the conduction band (CB) $\mathrm{ZnO}$ to $\mathrm{TiO}_{2}$, while $\mathrm{h}^{+}$transfers from the valence band (VB) of $\mathrm{TiO}_{2}$ to $\mathrm{ZnO}$. As a result, an efficient separation of photogenerated electron and hole pairs at the core-shell heterojunction interface of $\mathrm{ZnO}$ and $\mathrm{TiO}_{2}$ is reached [29]. These electron and hole pairs improve the occurrence of redox processes; electrons reduce dissolved $\mathrm{O}_{2}$ to ${ }^{\circ} \mathrm{O}_{2}{ }^{-}$, while $\mathrm{h}^{+}$forms $\mathrm{HO}^{\circ}$. Thus, $\mathrm{MB}$ molecules will be easily decomposed into $\mathrm{CO}_{2}$ and $\mathrm{H}_{2} \mathrm{O}$ by the 
strong oxidizer-reducer through some oxidation-reduction reactions.

\section{Conclusion}

In summary, we have reported a facile, green, efficient meth-

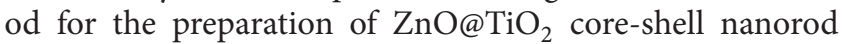
arrays grown on $\mathrm{Zn}$ wafer. The product has highly uniform structures over a large area. It is shown that the product has excellent photocatalytic activities for the degradation of $\mathrm{MB}$ under UV light illumination when compared with the performance of the $\mathrm{ZnO}$ nanorod arrays grown on $\mathrm{Zn}$ wafer. This is because the $\mathrm{ZnO} @ \mathrm{TiO}_{2}$ core-shell structure heterojunction can improve electron-charge separation efficiency. So, the proposed route to prepare the $\mathrm{ZnO} @ \mathrm{TiO}_{2}$ core-shell nanorod arrays represents a significant advance for the degradation of organic pollutants in water. In addition, compared with some nanoscale catalyst particles, the $\mathrm{ZnO} @ \mathrm{TiO}_{2}$ film with a coreshell structure has unique advantages for practical applications from the aspect of long life low-cost and high degradation efficiency. When $\mathrm{TiO}_{2}$ nanoparticles are coated on the surface of $\mathrm{ZnO}$ nanorod arrays, it is very convenient to separate or recover them in water purification processes. Recycling of photocatalyst in nanometer scale from the environmental system is an important focus in practical applications [30]. So, our proposed route to prepare $\mathrm{ZnO@} \mathrm{TiO}_{2}$ core-shell structure catalysts represents a very important advance for environmental remediation applications.

\section{Conflicts of Interest}

The authors declare that there are no conflicts of interest regarding the publication of this paper.

\section{Acknowledgments}

This research was supported by the National Natural Science Foundation of China (51302102 and 11504120), the Natural Science Foundation of Anhui Province (1708085ME96), the Key Natural Science Research Project for Colleges and Universities of Anhui Province (KJ2016A638 and KJ2016SD51), the Huaibei Scientific Talent Development Scheme (20140305 and 20140318), and the Huaibei Normal University Youth Research Project (2014xq017).

\section{References}

[1] X. Li, J. Zhu, and B. Wei, "Hybrid nanostructures of metal/twodimensional nanomaterials for plasmon-enhanced applications," Chemical Society Reviews, vol. 45, no. 11, pp. 3145-3187, 2016.

[2] Y. Zhang, Y. Ye, X. Zhou et al., "Monodispersed hollow aluminosilica microsphere@hierarchical $\gamma$-AlOOH deposited with or without $\mathrm{Fe}(\mathrm{OH})_{3}$ nanoparticles for efficient adsorption of organic pollutants," Journal of Materials Chemistry A, vol. 4, no. 3, pp. 838-846, 2016.

[3] S. Guo, X. Li, J. Zhu, T. Tong, and B. Wei, “Au NPs@MoS submicrometer sphere-ZnO nanorod hybrid structures for efficient photocatalytic hydrogen evolution with excellent stability," Small, vol. 12, no. 41, pp. 5692-5701, 2016.
[4] M.-H. Yeh, L.-Y. Lin, C.-Y. Chou et al., "Preparing core-shell structure of ZnO@TiO2 nanowires through a simple dippingrinse-hydrolyzation process as the photoanode for dye-sensitized solar cells," Nano Energy, vol. 2, no. 5, pp. 609-621, 2013.

[5] D. Guo, J. Wang, C. Cui et al., "ZnO@TiO2 core-shell nanorod arrays with enhanced photoelectrochemical performance," Solar Energy, vol. 95, pp. 237-245, 2013.

[6] X. Yan, C. Zou, X. Gao, and W. Gao, " $\mathrm{ZnO} / \mathrm{TiO} 2$ core-brush nanostructure: processing, microstructure and enhanced photocatalytic activity," Journal of Materials Chemistry, vol. 22, no. 12, pp. 5629-5640, 2012.

[7] M. Law, L. E. Greene, A. Radenovic, T. Kuykendall, J. Liphardt, and $\mathrm{P}$. Yang, "ZnO-Al2O3 and $\mathrm{ZnO}-\mathrm{TiO} 2$ core-shell nanowire dye-sensitized solar cells," Journal of Physical Chemistry B, vol. 110, no. 45, pp. 22652-22663, 2006.

[8] M. Wang, C. Huang, Y. Cao et al., "The effects of shell characteristics on the current-voltage behaviors of dye-sensitized solar cells based on $\mathrm{ZnO} / \mathrm{TiO}_{2}$ core/shell arrays," Applied Physics Letters, vol. 94, no. 26, Article ID 263506, 2009.

[9] R. Wang, H. Tan, Z. Zhao et al., "Stable ZnO@TiO2 core/shell nanorod arrays with exposed high energy facets for self-cleaning coatings with anti-reflective properties," Journal of Materials Chemistry A, vol. 2, no. 20, pp. 7313-7318, 2014.

[10] H. M. A. Javed, W. Que, X. Yin, Y. Xing, J. Shao, and L. B. Kong, " $\mathrm{ZnO} / \mathrm{TiO} 2$ nanohexagon arrays heterojunction photoanode for enhancing power conversion efficiency in dye-sensitized solar cells," Journal of Alloys and Compounds, vol. 685, pp. 610618, 2016.

[11] F. Kayaci, S. Vempati, C. Ozgit-Akgun, I. Donmez, N. Biyikli, and T. Uyar, "Selective isolation of the electron or hole in photocatalysis: $\mathrm{ZnO}-\mathrm{TiO} 2$ and $\mathrm{TiO} 2-\mathrm{ZnO}$ core-shell structured heterojunction nanofibers via electrospinning and atomic layer deposition," Nanoscale, vol. 6, no. 11, pp. 5735-5745, 2014.

[12] M. Pazoki, N. Nafari, and N. Taghavinia, "Ab initio study of electronic effects in the $\mathrm{ZnO} / \mathrm{TiO} 2$ core/shell interface: application in dye sensitized solar cells," RSC Advances, vol. 4, no. 1, pp. 301-307, 2014.

[13] D. Barreca, E. Comini, A. P. Ferrucci et al., "First example of $\mathrm{ZnO}-\mathrm{TiO} 2$ nanocomposites by chemical vapor deposition: structure, morphology, composition, and gas sensing performances," Chemistry of Materials, vol. 19, no. 23, pp. 5642-5649, 2007.

[14] R. S. Mane, W. J. Lee, H. M. Pathan, and S.-H. Han, "Nanocrystalline $\mathrm{TiO} 2 / \mathrm{ZnO}$ thin films: fabrication and application to dyesensitized solar cells," Journal of Physical Chemistry B, vol. 109, no. 51, pp. 24254-24259, 2005.

[15] J. Ren, W. Que, X. Yin, Y. He, and H. M. A. Javed, "Novel fabrication of $\mathrm{TiO} 2 / \mathrm{ZnO}$ nanotube array heterojunction for dyesensitized solar cells," RSC Advances, vol. 4, no. 15, pp. 74547460, 2014.

[16] C. Lévy-Clément, R. Tena-Zaera, M. A. Ryan, A. Katty, and G. Hodes, "CdSe-sensitized p-CuSCN/nanowire n-ZnO heterojunctions," Advanced Materials, vol. 17, no. 12, pp. 1512-1515, 2005.

[17] Z. Lou, J. Deng, L. Wang, R. Wang, T. Fei, and T. Zhang, "A class of hierarchical nanostructures: $\mathrm{ZnO}$ surface-functionalized TiO2 with enhanced sensing properties," RSC Advances, vol. 3, no. 9, pp. 3131-3136, 2013.

[18] J. Arin, S. Thongtem, and T. Thongtem, "Single-step synthesis of $\mathrm{ZnO} / \mathrm{TiO} 2$ nanocomposites by microwave radiation and their photocatalytic activities," Materials Letters, vol. 96, pp. 78-81, 2013. 
[19] M. Wang, C. Huang, Y. Cao et al., "A plasma sputtering decoration route to producing thickness-tunable $\mathrm{ZnO} / \mathrm{TiO}_{2}$ core/shell nanorod arrays," Nanotechnology, vol. 20, no. 28, Article ID 285311, 2009.

[20] C. W. Zou, X. D. Yan, J. Han et al., "Preparation and enhanced photoluminescence property of ordered $\mathrm{ZnO} / \mathrm{TiO} 2$ bottlebrush nanostructures," Chemical Physics Letters, vol. 476, no. 1-3, pp. 84-88, 2009.

[21] L. E. Greene, M. Law, B. D. Yuhas, and P. Yang, "ZnO-TiO2 core-shell nanorod/P3HT solar cells," Journal of Physical Chemistry C, vol. 111, no. 50, pp. 18451-18456, 2007.

[22] M. Wang, C.-H. Ye, Y. Zhang et al., "Synthesis of well-aligned $\mathrm{ZnO}$ nanorod arrays with high optical property via a low-temperature solution method," Journal of Crystal Growth, vol. 291, no. 2, pp. 334-339, 2006.

[23] Y. Su, J. Yu, and J. Lin, "Vapor-thermal preparation of highly crystallized $\mathrm{TiO}_{2}$ powder and its photocatalytic activity," Journal of Solid State Chemistry, vol. 180, no. 7, pp. 2080-2087, 2007.

[24] T. A. Egerton, "Uv-absorption-the primary process in photocatalysis and some practical consequences," Molecules, vol. 19, no. 11, pp. 18192-18214, 2014.

[25] M. Zhang, T. An, X. Liu, X. Hu, G. Sheng, and J. Fu, "Preparation of a high-activity $\mathrm{ZnO} / \mathrm{TiO} 2$ photocatalyst via homogeneous hydrolysis method with low temperature crystallization," Materials Letters, vol. 64, no. 17, pp. 1883-1886, 2010.

[26] R. Wang, X. Xu, Y. Zhang, Z. Chang, Z. Sun, and W.-F. Dong, "Functionalized ZnO@TiO2 nanorod array film loaded with ZnIn0.25Cu0.02S1.395 solid-solution: synthesis, characterization and enhanced visible light driven water splitting," Nanoscale, vol. 7, no. 25, pp. 11082-11092, 2015.

[27] A. Van Dijken, A. H. Janssen, M. H. P. Smitsmans, D. Vanmaekelbergh, and A. Meijerink, "Size-selective photoetching of nanocrystalline semiconductor particles," Chemistry of Materials, vol. 10, no. 11, pp. 3513-3522, 1998.

[28] B. Neppolian, H. C. Choi, S. Sakthivel, B. Arabindoo, and V. Murugesan, "Solar/UV-induced photocatalytic degradation of three commercial textile dyes," Journal of Hazardous Materials, vol. 89, no. 2-3, pp. 303-317, 2002.

[29] N. Serpone, P. Maruthamuthu, P. Pichat, E. Pelizzetti, and H. Hidaka, "Exploiting the interparticle electron transfer process in the photocatalysed oxidation of phenol, 2-chlorophenol and pentachlorophenol: chemical evidence for electron and hole transfer between coupled semiconductors," Journal of Photochemistry and Photobiology, A: Chemistry, vol. 85, no. 3, pp. 247255, 1995.

[30] W. Smith and Y. P. Zhao, "Superior photocatalytic performance by vertically aligned core-shell $\mathrm{TiO}_{2} / \mathrm{WO}_{3}$ nanorod arrays," $\mathrm{Ca}$ talysis Communications, vol. 10, no. 7, pp. 1117-1121, 2009. 

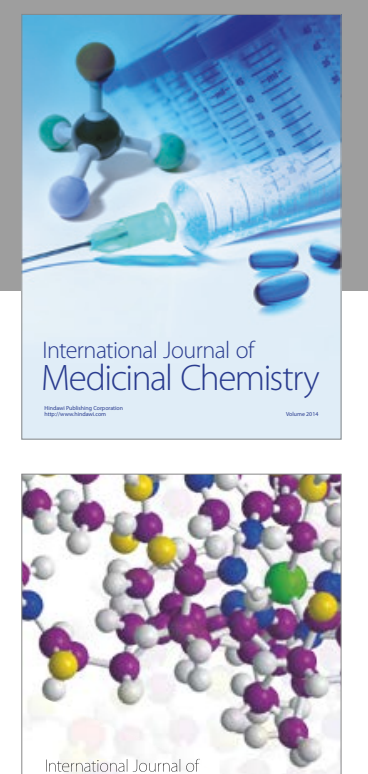

Carbohydrate Chemistry

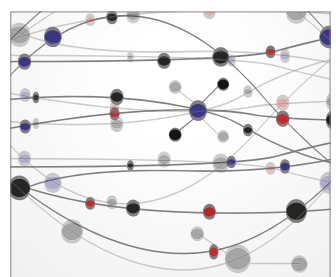

The Scientific World Journal
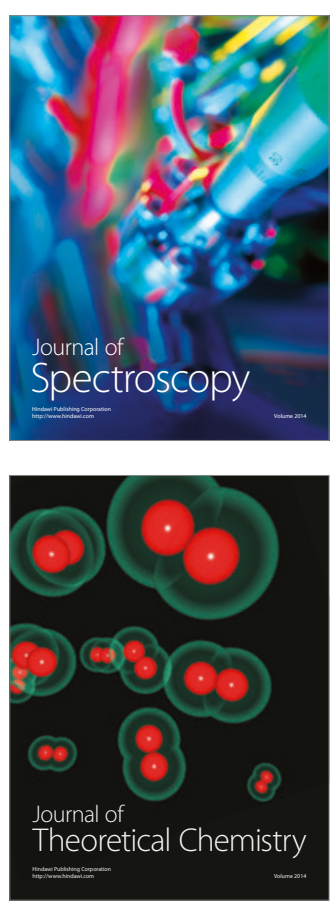
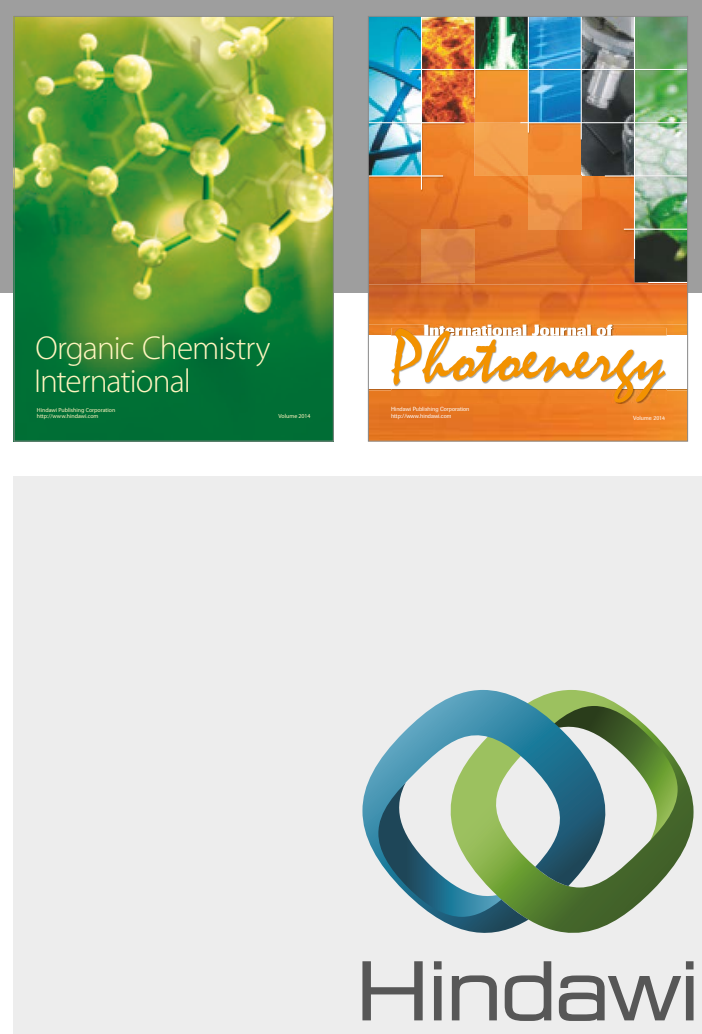

Submit your manuscripts at

https://www.hindawi.com

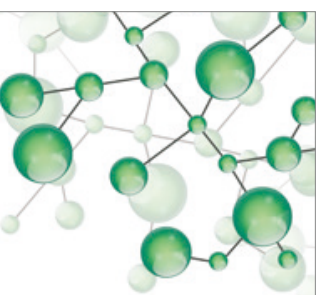

International Journal of

Inorganic Chemistry

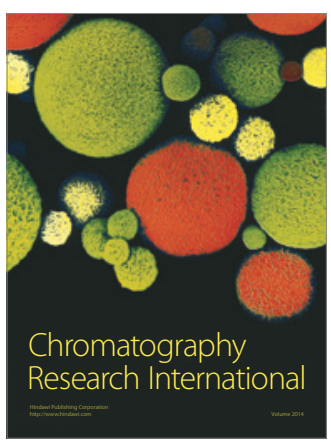

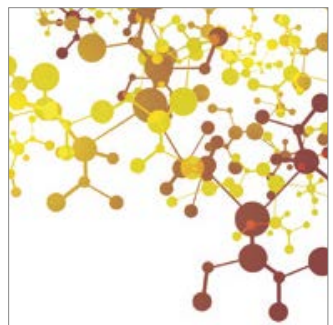

Applied Chemistry
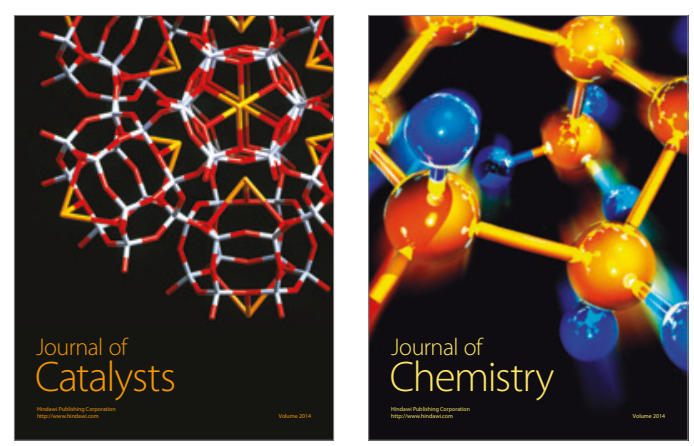
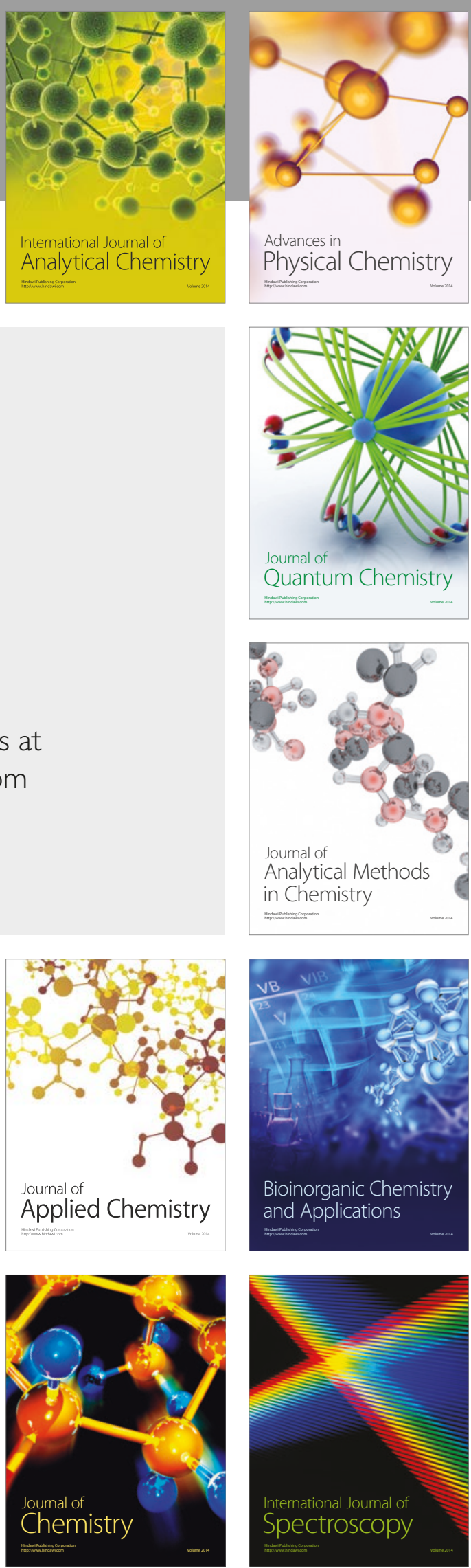